\title{
Manipulating pH in Cancer Treatment: Alkalizing Drugs and Alkaline Diet
}

\author{
Longhi Alessandra* \\ ${ }^{\text {It }}$ Ortopedico Rizzoli, Bologna, Italy
}

Submission: March 14, 2017; Published: April 20, 2017

*Corresponding author: Longhi Alessandra MD, Ist Ortopedico Rizzoli, Bologna, Italy, Email: longhi.alessandra@libero.it

\begin{abstract}
Neoplastic cells have inverted $\mathrm{pHi} / \mathrm{pHe}$ gradient compared to a normal cell and a higher acid extracellular micro environment is a feature of cancer tissue. It is well known the role of acidity in cancer growth and metastatization. Many research studies have been undertaken and even more are ongoing to study the possibility to interfere with cancer cell growth modifying the intracellular or extracellular $\mathrm{pH}$ with different mechanisms. Different drugs that inhibit $\mathrm{H}+$ intracellular extrusion via membrane proton pumps inhibitors or mitochondrial poisons that increase intracellular acidity have been tested in cancer cells in preclinical studies, human studies are very few but promising.

Some literature underlines the value of alkaline diet as co-adjuvant for cancer treatment, but human randomized studies on the effectiveness of alkaline diet or alkaline water are lacking. We have to understand if it is possible and how to translate the laboratory results in clinical results in cancer patients.
\end{abstract}

\section{Introduction}

\section{The rationale for alkalizing $\mathrm{pH}$ in cancer microenvironment}

The increased acidity of tumor tissue is due to:

A. Increased production al lactate due to the increased anaerobic glycolytic pathway used by cancer cells (Warburg effect).

B. Hypoxia due to low 02 concentration due to hypo perfusion [1].

Neoplastic cells have an intracellular $\mathrm{pH}(\mathrm{pHi}) /$ extracellular $\mathrm{pH}(\mathrm{pHe})$ gradient inverted compared to normal cells. Normal cells usually have a slightly acid pHi (6.99-7.05) and a more alkaline pHe (7.3-7.4). In neoplastic cells the pHi is more alkaline (7.1-7.7) and the pHe is more acid (6.2-6.9) [2]. The development and maintenance of this reversed $\mathrm{pH}$ gradient are directly owing to the proton $(\mathrm{H}+)$ secretory ability of the tumor cells. This proton secretion depends on the buffering capacity of the cell and it is driven by a series of transporters and enzymes that helps to keep the pHi in alkaline range and expel the excess of acidity in the extracellular environment.

The acidity of extracellular environment is essential for cancer cell proliferation, for invasion and metastatization and it also plays a role in chemotherapy and radiotherapy resistance
$[3,4]$ Besides, acidity of extracellular environment has a role in inhibition of Natural Killer and T cytotoxic lymphocytes [5,6]. In order to survive in a low pH-environment tumor cells develop regulatory mechanisms which keep their intracellular $\mathrm{pH}$ stable [7].

Several preclinical studies have shown how an inhibition of these regulatory systems (pumps transporters) can reverse the pHe acidity in cancer and increase the pHi acidity that cause apoptosis. The inhibition of these pump transporters can be obtained with commonly used drugs such as PPInhibitors, Sodium Bicarbonate, amiloride, acetazolamide that can reverse the $\mathrm{pH}$ gradient increasing the intracellular $\mathrm{H}$ concentration and subsequent acidity as shown in preclinical studies [8,9].

The most important systems to keep intracellular / extracellular $\mathrm{H}$ ion gradient stable are:
A. Vacuolar ATPase proton pump.
B. The sodium-proton exchanger family (NHE),
C. The bicarbonate transporter family (BCT)
D. The mono carboxylate transporter family (MCT)
E. Carbonic anidrase 9 (CAIX)
F. Voltage gated Sodium channel (VGSC) (Figure 1) 


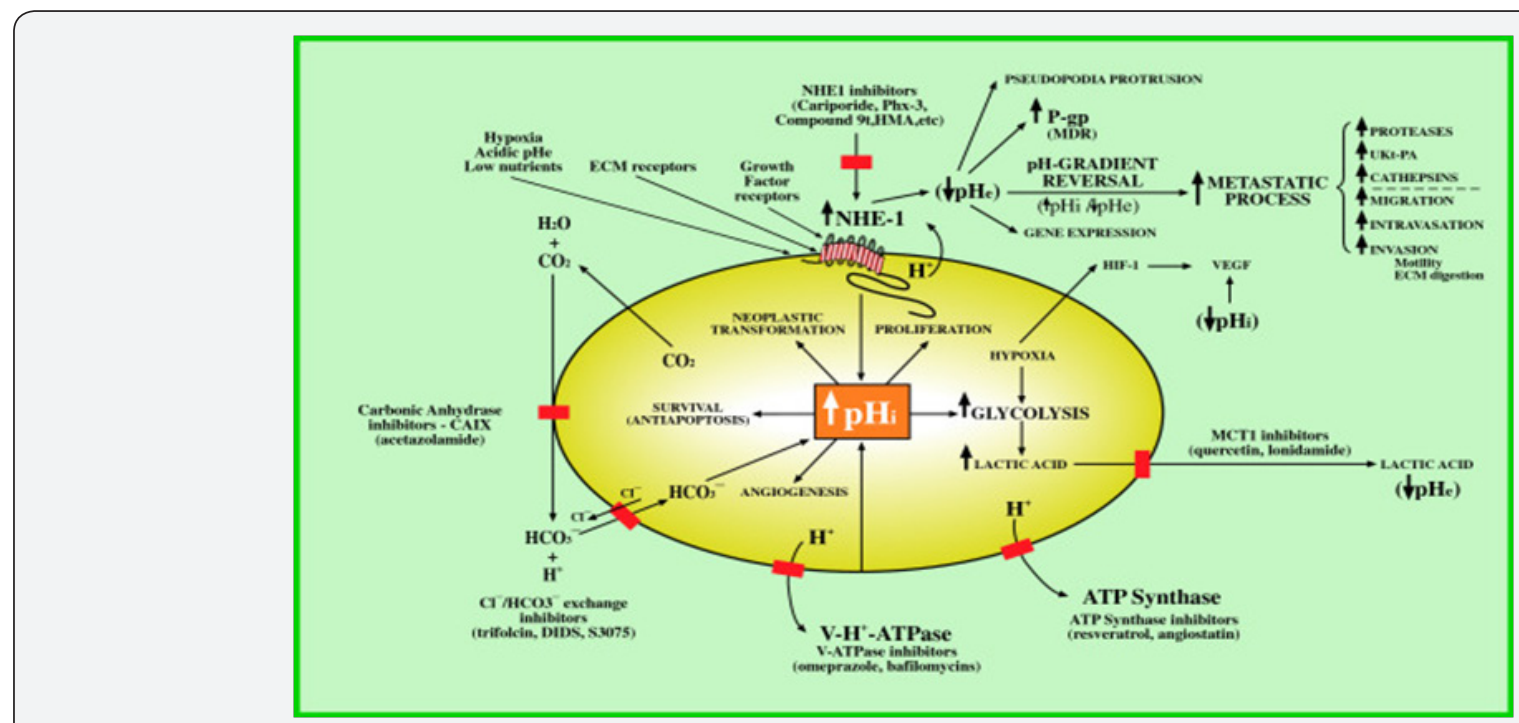

Figure 1: Targets for proton transport inhibitors (PTIs) as anticancer agents ( Harguinday S ) [33].

V-ATPases proton pumps acidify the extracellular compartment through proton extrusion and consequently increase cytoplasmic pH. Proton Pump Inhibitors (PPI) are drugs that inhibit Vacuolar ATPase proton pump. PPI is used in gastro protection therapy (lansoprazole, omeprazole, etc.) and there are few RCT ongoing (http//clinicaltrials.gov) with PPI in breast cancer, prostate cancer and in patients with other solid tumor in combination with chemotherapy to explore the therapeutic activity of PPI. The long term administration of ion pump inhibitors, which is a selective target of anticancer therapy, studied in vitro, showed that they are able to suppress tumor growth [10].

NHE-1 (the sodium-proton exchanger family) have an increased activity in cancer cells with the result of a rise of intracellular $\mathrm{pH}$ and a reduction of extracellular $\mathrm{pH}$ of tumor tissue. Amiloride is one NHE inhibitor and is a commonly prescribed diuretic. Monocarboxylate 4 (MCT 4) transporter family is a transporter that export lactate (result of glycolysis ) outside cell and it is overexpressed in cancer cell and can be inhibited by several compound like statin, quercetin.

Carbonic anhydrase 9 (CAIX) are hypoxia inducible enzymes that catalyze extracellular $\mathrm{CO} 2$ to become $\mathrm{HCO} 3$ (bicarbonate ion) and maintain an elevated intracellular $\mathrm{pH}$. There are few CA isoforms CAIX and CA XII are associated with tumor and are over expressed in tumors [11]. Acetazolamide (a diuretic) is a CAIX inhibitor. Since cancer cells are continuously producing acidity, increasing intracellular acidity by blocking the major membrane transporters above mentioned can increase apoptosis due to intracellular hyperacidity. Increasing pHi acidity can be obtained also by increasing the production of acidity by some mitochondrial poisons that inhibit the oxidative phosphorylation, increase aerobic glycolysis and finally increase $\mathrm{H}+$ ion production (such drugs are metformin, doxycycline) [7].
The hypothesis of increasing intracellular acidity by increasing production of $\mathrm{H}+$ combined with the decrease $\mathrm{H}+$ extrusion blocking the pump transporter with PPI, NHE inhibitors, CAIX, MCT4 is manageable with approved drugs that could be used in association. Some preclinical studies have been made buffering extracellular acidity with different substances like sodium bicarbonate or with cell ion transporters inhibitors. These studies showed a decrease of tumor growth [12] and an improvement of the immune system response (increased tumor infiltration by lymphocytes) [13].

Some studies showed that an alkaline extracellular environment can enhance chemosensitivity of some chemotherapeutic drugs like anthracycline. The weak bases mitoxantrone, daunorubicin and doxorubicin all showed enhanced cytotoxicity at higher pHe values. Conversely, the weak acids chlorambucil, cyclophosphamide and 5-fluorouracil all showed enhanced cytotoxicity at low pHe values [14]. So not all chemotherapeutic drugs may benefit of the same extracellular $\mathrm{pH}$. Nowadays many patients have chronic pathologies that needs therapy with statins, amiloride, PPI and other compounds of those above mentioned for which a potential protective effect against cancer has been demonstrated in preclinical studies. Epidemiologic researches on PPI, amiloride, acetazolamide employed in cancer patients for comorbidity could be interesting.

\section{Human studies with cell membrane proton pump and proton transporter inhibitors}

Few studies have been conducted on human being exploring the effect of alkalizing of tumor microenvironment In one study Gillies et al employed $\mathrm{Na}$ bicarbonate at the equivalent doses used in experimental mice $(0,6 \mathrm{~g} / \mathrm{kg}$ or $0,5 \mathrm{~g} / \mathrm{kg})$ Due to side effects of metabolic alkalosis patients interrupted the therapy (Springett G, Gillies RJ 2010, NCT01198821) [15]. A randomized study was conducted with intermittent high dose of 
PPI in metastatic breast cancer in combination treatment with chemotherapy (Docetaxel and Cisplatin for 6 cycles). The group who received intermittent high doses of esomeprazole (a PPI) had a significant better Overall Survival and Time To Progression and Overall response Rate was $67.7 \%$ in PPI arm vs $46.9 \%$ (only chemotherapy group) [16].

One case reports of PPI (rabeprazole) employed as a unique therapy in 3 advanced Gastrointestinal cancer patients refractory to standard therapy reported a long term stabilization of advanced disease [17]. Harguindey S reported on a case of advanced ovarian cancer who reached a prolonged survival with only Amiloride (NHE inhibitor) supplementation with decrease of tumor marker [18]. We need RCT in cancer patients exploring the effectiveness of these pump cell transporters alone or in combination (ie amiloride+lansoprazole+acetazolamide) and we need to explore if the association of these drugs with chemotherapy, radiotherapy can improve the effectiveness of chemotherapy. The first study to explore the enhancement of activity of chemotherapy subsequent to pretreatment with high-dose PPIs in humans has been carried out in patients with osteosarcoma [19]. In this not randomized phase II trial, 98 patients received esomeprazole $(60 \mathrm{mg} /$ day) for 2 days before neoadjuvant treatment with methotrexate, cisplatin, and adriamycin. It was reported a higher percentage of tumor necrosis with respect to historical controls. The highest percentage of the tumor necrosis rate was in a cohort of patients with chondroblastic osteosarcoma, where the expected response rate is usually extremely low.

A randomized trial in 66 advanced gastrointestinal cancer patients receiving PPI (rabeprazole 1,5mg/kg bid for 3d/week) plus metronomic Capecitabine $1500 \mathrm{mg} / \mathrm{d}$ vs Capecitabine alone is ongoing [20]. We also need to find validated instruments (markers) to verify that alkalizing is obtainable in the tumor microenvironment thanks to these treatments.

\section{Alkaline Diet and Cancer}

The western diet is rich of animal protein. Alkaline foods include nearly all vegetables and fruits, many nuts and seeds, An alkaline diet, based mainly on alkaline foods can affect the acidity of body fluids, including the urine or blood. Acid forming foods are high-protein foods, especially from animal source like meat, fish, and eggs and most legumes, such as beans and peas. Sugar, alcohol, and most cereals are also acid forming.

Alkaline food sources are rich in cations-sodium (Na+), potassium $(\mathrm{K}+)$, calcium $(\mathrm{Ca} 2+)$, and magnesium $(\mathrm{Mg} 2)$. On the other hand, acid foods or supplemental sources are negative ions like phosphate (PO4-), sulfate (SO4-), chloride (Cl-), and organic acids-that cause metabolic academia. A balanced diet with adequate amount of protein $(0.8 \mathrm{~g} / \mathrm{kg})$ and abundant vegetables and fruit has been proved to be important for bone health. The body keeps a balance of blood $\mathrm{pH}$ through a refined system of alkaline acid homeostasis through kidney and lung and in case of an alkaline diet can decrease calciuria and exert a protective effect on bone. Few studies showed the effect of alkaline compounds (potassium citrate i.e,) in decreasing bone resorption [21]. On the contrary and in case of prevalent acid diet or in an acid environment (as it occur in kidney failure ) calciuria increases and could be harmful to bone health.

A lot of papers have been published about diet an cancer in the last two decades and many researches are ongoing: in nci. clinicaltrials.gov under "dietand cancer treatment" thereare more than 1000 studies. Many epidemiologic studies have underlined how diet can influence health and cancer risk. Epidemiologic studies (like EPIC studies) showed that a more vegetarian whole grain diet (as Mediterranean diet) is healthier compared to western diet based on animal proteins in cancer prevention.. Most epidemiologic studies showed the role of a whole grain plant based diet also as a secondary cancer prevention in some cancer like breast cancer (like the WINS study) and colon cancer [22]. Observational studies have shown that diet can influence progression and relapse in oncologic survivors [23]. Study in breast cancer survivors who followed the nutrition and lifestyle recommendations of American Cancer Soc. Demonstrated a better prognosis [24]. An open question is if an alkaline diet or alkaline drinking water during chemotherapy or radiotherapy can improve outcome. There are very few studies on alkaline diet or alkaline water during cancer treatment despite a very popular in lay press.

Brewer reported of areas in the world where cancers incidence are very low. These areas have concentrations of alkalizing minerals in the soil and water greater than in other parts of the world. For example, the Hunza of northern Pakistan and the Hopi Indians of the West American share both similar soil and water conditions. The alkaline minerals like of cesium chloride, germanium are heavily present in the soil and water. These peoples also live in similar high, dry climates traditionally eating the fresh or dried fruit and the seeds each day [25].

Raghunand [25] published the first in vivo demonstration through 31P-magnetic resonance spectroscopy (MRS) that the pHe of MCF-7 human breast cancer xeno grafts can be effectively and significantly raised with sodium bicarbonate in drinking water. Also the bicarbonate-induced extracellular alkalinization leads to significant improvements in the therapeutic effectiveness of doxorubicin against MCF-7 xeno grafts in vivo. Another preclinical study showed that sodium bicarbonate added to drinking water in TRAMP mice dramatically delayed the transition from in situ to invasive prostate cancer [26].

A phase II ongoing trial is studying how well alkaline water works in reducing skin toxicity in women with breast cancer undergoing radiation therapy. Alkaline water may reduce radiation therapy-related skin toxicity in patients with breast (www.clinicaltrials.govNCT01487954) [27]. Some researches 


\section{Journal of Complementary Medicine \& Alternative Healthcare}

found that certain antiblastic drugs are more active in alkaline environment (doxorubicine) [28] while others (alkilants, cisplatin) are more efficient in an acid extracellular environment [29]. Despite many preclinical studies few well conducted human studies are available.

A recent systematic review was conducted by Fenton [30]. The study aim was an analysis of observational studies with either varying acid-base dietary intakes and/or alkaline water in relation to incidence of cancer or cancer treatment outcome. Only one study met the inclusion criteria with a low risk of bias. This study revealed no association between the diet acid load with bladder cancer (OR=1.15, 95\% CI $0.86-1.55$, p=0.36) [31].

\section{Conclusion}

So despite very promising preclinical data that favor the hypothesis that alkalinization through different drugs that inhibit cellular pumps can improve the outcome of cancer, we do not have at the moment the same evidence based studies on human beings. Also in the employ of alkaline diet or alkaline water during cancer treatment in the attempt to improve cancer patient's outcome we do not have at the moment enough strong studies. While the value of an alkaline diet has been proved into prevention or improvement of some chronic diseases [32] and in primary and secondary cancer prevention its value during cancer treatment is less clear. Randomized clinical trial should be designed to verify the hypothesis that alkaline diet vs western diet alone or in combination with buffering-alkalizing drugs during chemotherapy/radiotherapy can improve response to chemotherapy and outcome [33].

\section{References}

1. Martinez-Zaguilan R, Seftor EA, Seftor RE, Chu YW, Gillies RJ, et al (1996) Acidic $\mathrm{pH}$ enhances the invasive behavior of human melanoma cells. Clin Exp Metastasis 14(2): 176-186.

2. Reshkin SJ, Greco MR, Cardone RA (2014) Role of pHi, and proton transporters in oncogene-driven neoplastic transformation. Philos Trans R Soc B 369: 20130100.

3. Raghunand N, Mahoney B, van Sluis R, Baggett B, Gillies RJ (2001) Acute metabolic alcalosis enhances response of $\mathrm{C} 3 \mathrm{H}$ mouse mammary tumors to the weak base mitoxantrone. Neoplasia 3(3): 227-235.

4. Doyen J P, SK Marcié, S Pouysségur J, Chiche J (2012) Knock-down of hypoxia-induced carbonic anhydrases IX and XII radiosensitizes tumor cells by increasing intracellular acidosis. Front Oncol 2(199): 1-10.

5. Lardner A (2001) The effects of extracellular $\mathrm{pH}$ on immune function. J Leukoc Biol 69(4): 522-530.

6. Fischer K, Hoffmann P, Voelkl S, Meidenbauer N, Ammer J, et al. (2007) Inhibitory effect of tumor cell-derived lactic acid on human $\mathrm{T}$ cells. Blood 109(9): 3812-3819.

7. Koltai $\mathrm{T}$ (2016) Cancer: fundamentals behind $\mathrm{pH}$ targeting and the double-edged approach. OncoTargets and Therapy 9: 6343-6360.

8. Fais S, De Milito A, You H, Qin W (2007) Targeting vacuolar H+ ATPases as a new strategy against cancer. Cancer Res 67(22): 10627-10630.

9. Izumi $\mathrm{H}$, Torigoe T, Ishiguchi $\mathrm{H}$, Uramoto H, Yoshida $\mathrm{Y}$, et al. (2003) Cellular $\mathrm{pH}$ regulators: potentially promising molecular targets for cancer chemotherapy. Cancer Treat Rev 29(6): 541-549.

10. Harguindey S, Arranz JL, Wahl ML, Orive G, Reshkin SJ ( 2009) Proton transport inhibitors as potentially selective anticancer drugs. Anticancer Res 29(6): 2127-2136.

11. Mahon BP, Pinard MA, McKenna R (2015) Targeting carbonic anhydrase IX activity and expression. Molecules 20(2): 2323-2348.

12. Robey IF, Baggett BK, Kirkpatrick ND, Roe DJ, Dosescu J, et al. (2009) Bicarbonate increases tumor $\mathrm{pH}$ and inhibits spontaneous metastases. Cancer Res 69(6): 2260-2268.

13. Pilon-Thomas S, Kodumudi KN, El-Kenawi AE, Russell S, Weber AM, et al. ( 2015) Neutralization of tumor acidity improves antitumor responses to immunotherapeutic interventions. Cancer Res 76(6): $1381-1390$

14. Mahoney BP, Raghunand N, Baggett B, Gillies RJ (2003) Tumor acidity, ion trapping and chemotherapeutics. I. Acid $\mathrm{pH}$ affects the distribution of chemotherapeutic agents in vitro. Biochem Pharmacol 66(7): 12071218.

15. Springett G, Gillies RJ (2010) Gem-TABS in unresectable pancreatic cancer ClinicalTrials.

16. Wang BY, Zhang J, Wang JL (2015) Intermittent high dose proton pump inhibitor enhances the antitumor effects of chemotherapy in metastatic breast cancer. J ExpClin Cancer Res 34(1): 85.

17. Falcone R, Roberto M, D’Antonio C (2016) High-doses of proton pump inhibitors in refractory gastro-intestinal cancer: A case series and the state of art. Dig Liver Dis 48(12): 1503-1505.

18. Harguindey S, Orive, Pedraz JL (2003) Long term remission of metastatic ovarian cancer after chronic treatment with the $\mathrm{Na}+-\mathrm{H}+$ antiport inhibitor amiloride. Oncologia 26(5): 123-127.

19. Ferrari S, Perut F, Fagioli F (2013) Proton pump inhibitor chemosensitization in human osteosarcoma: from the bench to the patients' bed. J Transl Med 11: 268-274.

20. Marchetti P, Milano A, D’Antonio C (2016) Association between Proton Pump Inhibitors and Metronomic Capecitabine as Salvage Treatment for Patients with Advanced Gastrointestinal Tumors: A Randomized Phase II Trial. Clinical Colorectal Cancer 15(4): 377-380

21. Gregory NS, Kumar R, Stein EM, Alexander E, Christos P, et al. (2015) Potassium Citrate decreases Bone resorption in postmenopausal women with osteopenia : a randomized ,double-blind clinical trial Endocr Pract 21(12) 1380-1386.

22. Blackburn GL, Wang KA (2007) Dietary fat reduction and breast cancer outcome: results from the Women's Intervention Nutrition Study (WINS). Am J ClinNutrn 86(3): 878-881.

23. Pekmezi DW, Demark-Wahnefried W (2011) Updated evidence in support of diet and exercise interventions in cancer survivors. Acta Oncol 50(2): 167-178.

24. Kroenke CH, Fung TT, Hu FB, Holmes MD (2005) Dietary patterns and survival after breast cancer diagnosis. J ClinOncol 23(36): 9295-9303.

25. Brewer A K (1984) The high pH therapy for cancer tests on mice and humans. Pharmacol Biochem Behav 21: 1-5.

26. Ibrahim-Hashim A, Cornnell HH, Abrahams D (2012) Systemic buffers inhibit carcinogenesis in TRAMP mice. J Urol 188(2): 624-631.

27. Raghunand N, He X, van Sluis R, Mahoney B, Baggett B (1999) Enhancement of chemotherapy by manipulation of tumour $\mathrm{pH}$. British Journal of Cancer 80(7): 1005-1011.

28. Song C, Griffin RJ, Heon JP () Influence of Tumor pH on Therapeutic Response. In book: Cancer Drug Resistance p. 21-42. 
29. Fenton TR, Huang T (2016) Systematic review of the association between dietary acid load, alkaline water and cancer. BMJ Open 6.

30. Wright ME, Michaud DS, Pietinen P (2005) Estimated urine pH and bladder cancer risk in a cohort of male smokers (Finland). Cancer Causes Control 16(9): 1117-1123.

31. Schwalfenberg GK (2012) The alkaline diet: is there evidence that an alkaline pH diet benefits health? J Environ Public Health 2012: 727630.

This work is licensed under Creative

Commons Attribution 4.0 Licens

DOI: 10.19080/JCMAH.2017.02.555580
32. Ribeiro M de LC, Silva AS, Bailey KM (2012) Buffer Therapy for Cancer. Journal of nutrition \& food sciences 2: 6 .

33. Harguinday S , Arranz JL, Orozco JD, Rauch C, Fais S, et al. (2013) Cariporide and other new and powerful NHE1 inhibitors as potentially selective anti cancer drugs- an integral molecular/biochemical/ metabolic/clinical approach after one hundred years of cancer research. Journal of Translational Medicine 11: 282.

\section{Your next submission with Juniper Publishers will reach you the below assets}

- Quality Editorial service

- Swift Peer Review

- Reprints availability

- E-prints Service

- Manuscript Podcast for convenient understanding

- Global attainment for your research

- Manuscript accessibility in different formats

( Pdf, E-pub, Full Text, Audio)

- Unceasing customer service

Track the below URL for one-step submission https://juniperpublishers.com/online-submission.php 